\title{
Raízes alemãs da sociologia econômica
}

Michel Lallement Apresentação e tradução de Leonardo Mello e Silva

Nota sobre sociologia econômica

Esteartigo éao mesmo tempo denso eoportuno, conquanto conciso eeconômico no talhe. D enso porque mobiliza fontes da sociologia clássica, esclarecendo passagens e influências às vezes pressupostas, porém nem sempre devidamente marcadas com a clareza e a precisão que 0 assunto - a imbricação entre os temas econômicos e os temas da organização social, passando pelo medium privilegiado do direito - exige. 0 portuno porque aponta, talvez involuntariamente, para implicações políticas mais próximas da agenda do presente, incluindo a aposta no cooperativismo e em uma economia social de mercado. A discussão sobre a vertente norte-americana do reformismo social, caldo de cultura da corrente institucionalista, e que dá empuxe à diferenciação do campo disciplinar chamado "sociologia econômica", é esclarecedora a esse respeito. Ela, aliás, abre uma brecha para se levantar a questão das condições sociais de eleição intelectual de determinadas classificações "sábias", como éo caso, sugerido no texto, para a American Economic Association. 0 recurso à história, aqui apenas roçado, éa fresta por onde se ilumina o que está de fato em jogo: lutas de classe, tendências monopolistas das firmas, desapossamento do saber de ofício, desemprego e crise social. Juntando os fios, é possível entrever, para a conjuntura de nascimento do institucionalismo (final do século XIX e as duas primeiras dé 
cadas do século XX), os outros componentes (não mencionados pelo autor) do quebra-cabeça: taylorismo, fordismo, crise do liberalismo e o "novo contrato social". Este artigo, portanto, estimula o paladar, se se pode dizer assim, e esse não é um mérito menor.

Com respeito àinfluência da escola histórica alemãna sociologia econômica - moteda contribuição - , o efeito éigualmenteestimulante. Seus esclarecimentos podem não ser originais, mas são certamenteabal izadose ponderados, confirmando elegantementea intuição dequeosargumentoshojeenfatizados pelo campo são devedores deuma problemática queestá posta em $M$ axW Wer eque, seassimé, o retorno àquela problemática(re)descobrirá muitoselosque a riqueza daquele patrimônio permiteestabelecer. U m exemplo: a relação entre as formas do direito (direito formal e direito material) e da organização econômica. $\mathrm{O}$ u ainda: entrecapitalismo etecnologias de poder. D ifícil, portanto, confinar tudo isso auma especialidade. 0 texto deM ichel Lallement é bom por causa dessa abertura.

Para a sociologia econômica em particular, assim como para a sociologia em geral, o tema das instituições constitui sem nenhuma dúvida um objeto seminal. Ainda que agreguem pontos de vista bastante diversificados (teoria doscustos detransação, escola da regulação, political economy, teoria dasconvenções...), as abordagensinstitucional istas reivindicadas peloseconomistas foram prova de uma vitalidade notável no curso dessesúltimos decênios (cf. H odgson, 1994). A sociologia conformou-sea essediapasão maistardiamentee, na falta deuma verdadei ra abordagem unificada, nota-se, sobretudo no período recente, igual mente discursos que reivindicam de maneira explícita um ponto de vista institucionalista (cf. Lallement, 2004a). Ratifica tal constatação o fato de, na presente contribuição, voltar-seàtemática institucionalista, que ocupa, como é de reconhecimento geral, um lugar importante no campo da sociologia econômica contemporânea. M inha tese maior é que, nessa matéria, somos grandemente devedores dos trabal hos ainda bastante desconhecidos hoje da escola histórica alemã. Tal escola ocupou um lugar central, para não dizer hegemônico, no seio do espaço intelectual alemão desdea metade do século XIX até os anos de 1920. N a tradição cameralista, ela assume uma amplidão em economia graças aos primeiros trabalhos de W ilhem Roscher, Karl Knies eBruno H ildebrand. Recordemos muito rapidamente suas causas e suas origens. 
Em 1843, W. Roscher publicauma pequena obra queafirma sua vontade de usar um método comparável àquele mobilizado por Friedrich Karl von Savigny, jurista que defende queo direito não éa emanação da Razão, masa expressão singular, atémesmo irracional, de experiências nacionais. Em um espírito similar, o objetivo dos economistas consistemenos em abstrair eem especular do queem descrever.

0 artigo defémetodológico da escola histórica, o artigo fundamental edistintivo, era dequeo organon da economia científica devia principalmente- no início sehavia dito exclusivamente- consistir nos resultados das monografias históricasenas generalizações que eram extraídas daí. Podese resumir precisamenteo credo da escola histórica pela proposição dequeo economista, considerado um pesquisador, deveser essencialmente um historiador da economia (Schumpeter, 1983, III, pp. 85-86).

Essa vontade de analisar os fatos econômicos sem abstraí-los do rico solo social, jurídico e histórico no qual germinam é, desde seu nascimento, uma constante da sociologia econômica. Para esclarecer mais precisamente 0 sentido e 0 alcance de tal asserção, há dois argumentos maiores que incitam a debruçar-se sobre as fontes germânicas. 0 primeiro é que $M$ ax Weber, figura das mais eminentes, mas também das mais ambíguas da escola histórica ${ }^{1}$, trabal hou abundantemente o campo de uma sociologia econômica (cf. Weber, 1999). Ainda que não o mais conhecido, um de seus resultados de maior importância consiste em dar atenção às regras e, mais exatamente, à articulação entre normas jurídicas e ação econômica. Em seus escritos consagrados à racionalização do direito, Weber desenvolve assim uma sólida reflexão sobre as condições sociais de gênese e de funcionamento da economia moderna. Essa problemática estará no coração da primeira parte da presente contribuição. 0 segundo argumento que me incita a voltar à Alemanha é o seguinte: nós hoje sem dúvida esquecemos, mas a escola histórica alemã emigrou de maneira fecunda para além de suas fronteiras, em direção notadamente à América do $\mathrm{N}$ orte. É impossível, por exemplo, compreender a entrada americana do institucionalismo sem antes se tomar consciência de que, a despeito da variedade de esquemas analíticos que pôde produzir, tal opção toma emprestadas da escola histórica al emã suas hipóteses de base. Seria preciso, para isso, de intermediários. 0 socioeconomista americano Richard Ely, autor bem menos renomado que Weber, foi um dos mais ativos dentre eles. Seus trabalhos serão apresentados na segunda parte. Limitando-me assim, de
1.Em Schumpeter (1983), Weber aparece como uma das figuras deproadaterceirageração daescolahistórica, ao lado de Arthur Spiethoff (especialista dos cicloseconômicos, que foi assistentedeSchmoller) e de Werner Sombart. Sobre as relações complexas de Weber com a escola histórica alemã ecom ateoria econômica austríaca, ver Lallement (2004b). 
maneira certamente parcial, aos trabalhos de Weber e de Ely, é à posteridade imediata das primeiras e das segundas escolas históricas que dedicarei meu interesse. Weber e Ely têm, com efeito, respirado a mesma atmosfera intelectual quando de seus estudos alemães, mas as contribuições de seus respectivos trabalhos para a sociologia econômica de ontem e de hoje inscrevem-se em registros tão diferentes quanto complementares.

Regras e instituições econômicas: a contribuição de MaxWeber

As múltiplas contribuições de $M$ ax W eber à sociologia econômica são hoje suficientemente conhecidas e não é necessário retomá-las em detal he (cf. Swedberg, 1998). M inha intenção é focalizar a atenção sobre um aspecto que se poderia ter como marginal, considerando-se por exemplo os grandes estudos do autor sobre a ética religiosa e as práticas econômicas, mas que reputo como particularmente esclarecedor na perspectiva institucionalista aqui priorizada. Trata-se, no caso, do estatuto das regras, em especial das regras de direito, na dinâmica econômica. A análise das transformações do direito no longuíssimo prazo permite esclarecer de maneira original a tese clássica da racionalização do mundo ocidental moderno.

\section{Fundamentos de uma sociologia do direito}

0 que se pode dizer sobre a evolução do direito, de um espaço social a outro, e como caracterizar suas formas múltiplas? A fim de responder a essa interrogação, Weber - que era jurista de formação e começou sua carreira como advogado - principia por distinguir direito formal de direito material. U ma lei é dita formal se pode ser deduzida de um sistema de noções e proposições por meio unicamente das regras da lógica. $N$ esse

2.0 direito formal é, em outros termos, um conjunto jurídico quese refere somente às pressuposições mesmas, ou postulados deum sistema jurídico dado. Ele conduz assim a umaracionalização do direito por razõespuramentejurídicas. caso, busca-se elaborar uma teoria jurídica na qual as normas obedeceriam exclusivamente à coerência da ordem jurídica abstrata e se deixariam deduzir umas das outras, al heias a toda consideração exterior (ética, política, religiosa, econômica... $)^{2}$. U ma lei é dita material se ela é conforme aos dados da ética, da religião, da economia, da política do momento: 0 direito material é, pois, um sistema que se refere a elementos extrajurídicos. D ito ainda de outro modo, esse direito tem em conta elementos não jurídicos, na medida em que não está a serviço de sua própria lógica abstrata e de sua coerência ideal, mas das exigências da sociedade histórica concreta cuja ordem ele regulamenta. W eber combina em seguida essa 
dicotomia com outra partição: aquela que opõe direito racional (uso de regras gerais) e direito irracional (que não emprega regras gerais). D aí, como indica a Q uadro 1, a obtenção de quatro tipos ideais de conformação do direito³.

QUADRO 1

Q uatro tiposideaisdedireito segundo M axWeber
3. Essatabelarecorreexplicitamenteaostermos utilizadospor G rosclaude em sua introdução (pp. 20 ss.) de Sociologie du droit, de Weber (1986).

\begin{tabular}{|c|c|c|}
\hline & DIREITO IRRACIONAL & DIRETO RACIONAL \\
\hline DIREITO MATERIAL & $\begin{array}{l}\text { Valores concretos restringindo-se ao caso particular, } \\
\text { em vez de normas gerais, são determinantes. Tal direi- } \\
\text { to se funda sobre o sentimento pessoal do juiz ou } \\
\text { sobre o arbítrio do déspota, sem referência a normas } \\
\text { gerais. É o caso, por exemplo, da justiça do cádi mu- } \\
\text { çulmano. }\end{array}$ & $\begin{array}{l}\text { Empregam-se princípios fornecidos por uma ideolo- } \\
\text { gia de natureza ética, política, religiosa. Tal direito e as } \\
\text { sentenças pronunciadas se referem a um livro sagrado } \\
\text { (como a Bíblia) ou ainda aos editos de um conquista- } \\
\text { dor, ou, por fim, a normas exteriores ao direito (mo- } \\
\text { ral, política, ideologia). }\end{array}$ \\
\hline DIREITO FORMAL & $\begin{array}{l}0 \text { juiz formaliza sua sentença fundando-se em meios } \\
\text { que não podem ser controlados pela razão (oráculo, } \\
\text { profecia, procedimentos mágicos). Exemplos: os } \\
\text { responsa dos jurisconsultos romanos e os julgamentos } \\
\text { ingleses do tipo Commentaries of the Law of England } \\
\text { (o juiz inglês é um verdadeiro "oráculo vivo" que res- } \\
\text { peita o procedimento, mas sua sentença tem efeito de } \\
\text { lei). }\end{array}$ & $\begin{array}{l}\text { O s julgamentos referem-se a precedentes, a um códi- } \\
\text { go, a um estatuto, portanto a regras sistematizadas e a } \\
\text { conceitos abstratos elaborados juridicamente. Podem- } \\
\text { se distinguir dois tipos: } \\
\text { Extrínseco: atribui-se uma significação jurídica a atos } \\
\text { concretos (um contrato é válido somente se toma a } \\
\text { forma escrita, um mandato ou citação só pode ser feito } \\
\text { por intermédio do meirinho). } \\
\text { Lógico: o direito exprime-se sob forma de regras, e } \\
\text { essas, por sua vez, por meio de conceitos abstratos } \\
\text { criados pelo próprio pensamento jurídico. }\end{array}$ \\
\hline
\end{tabular}

Em sua Rechtssoziologie, Weber distingue no essencial dois aspectos da racionalização do direito: um aspecto interno (dimensão formal da racionalização) e um aspecto externo (dimensão material). Essa distinção elementar tem para si a vantagem de favorecer a apresentação das teses de Weber e permite sobretudo trazer à tona a questão da racionalização econômica, em meio à qual as relações de trabal ho aparecem em lugar destacado.

\section{0 direito e a história}

Tome-se em primeiro lugar o caso da racionalização interna. É a dimensão em que nos demoraremosmenos. Para marcar as etapas determinantes dessa primeira forma de racional ização, Weber retém quatro estádios (cf. W eber, 1986, pp. 221 ss.). 0 ponto de partida é a revelação carismática do direito pelos profetas. 0 s exemplos típicos são o decálogo revelado por 
J eová a M oisés, os oráculos babilônicos ou helênicos, os druidas gauleses, os sacerdotes fetichistas africanos, o cádi muçulmano, o tirano, mas também o júri moderno. Esse direito éirracional e formal. Q ualificá-lo desse modo não significa que temos de nos defrontar com a aplicação de uma norma geral a um caso particular, mas antes a uma decisão cuja forma é válida para o caso considerado independentemente dos interesses ou do sentimento subjetivo de justiça. A produção da atividade jurídica passa em seguida - segundo estádio - para as mãos das notabilidades judiciárias (Rechthonorationen), a exemplo dos juízes ingleses ou dos jurisconsultos romanos. 0 direito é então concebido como uma série de problemas a resolver. A atividade jurídica permanece aqui em um nível muito concreto, donde o caráter ao mesmo tempo empírico e casuístico desse tipo de direito. 0 terceiro estádio corresponde ao desenvolvimento de comunidades políticas mais vastas e acarreta a aparição de poderes organizados de caráter teocrático (direito hindu, islâmico, israelita) ou principesco (direitos sagrados e legislações principescas do século XIX, por exemplo). 0 objetivo é arrancar o direito de seu irracionalismo, seja em nome de uma ética religiosa, seja em nome da razão de Estado, e isso com a finalidade de elaborar um direito de racionalidade material. $\mathrm{N}$ ão há, nesse caso, distinção entre moral e direito, entre exigência ética e princípios jurídicos. A extensão da atividade estatal, o interesse da burguesia e o desenvolvimento da burocracia acarretam por fim a aparição de juristas especial izados formados pela universidade. 0 direito tem então um caráter de racionalidade formal, uma vez que o trabalho legislativo é formalmente racional, na medida em que os fatos juridicamente importantes são determinados por meio de uma interpretação lógica significativa e que, em conformidade com essa última, conceitos jurídicos são produzidos e mobilizados sob forma de regras abstratas.

Evidentemente, o percurso não étão linear quanto sugere essa rápida re trospectiva, dependendo sobretudo, de um país a outro, de variáveis que condicionam o grau deformalização do direito. Weber retém três dessas variáveis: as relações entre Estado egrupos sociais (classes, ordens etc.), as relações entrepoderes teocráticose poderes profanose, por fim, a diversidadena estrutura dos notáveis de toga. A despeito das variações nacionais, três elementosterão jogado um papel determinantea favor da racionalização interna do direito. Em primeiro lugar, a ação dos práticosedos teóricos do direito. 0 direito romano é o primeiro que escapa da religião e torna-se uma técnica dominada por especialistas (os jurisconsultos) que empregam uma lingua- 
gem jurídica precisa. Inversamente, na Inglaterra, a racional ização do direito éretardada em função da ausência de uma burocracia e, conquanto se possa falar ali da existência de profissionais, esses últimos jamais elaboraram uma linguagem conceitualizada. A difusão da escrita - segundo fator - teve por efeito desorganizar ainterpretação carismática eirracional do direito. 0 scódigos são um meio de obrigar à consideração de precedentes, assim como à elaboração de regras como desdobramento deconflitos, afim deevitar outros conflitos. Weber considera que o código civil napoleônico constitui, juntamentecom o direito romano ea prática anglo-saxã, aterceiragrandefontede racional ização. Trata-sedeum direito essencialmenteurbano, escrito por legisperitos eclérigos. Plenamenteconstitutivo do fato burocrático, foi impulsionado pel os príncipes esenhores patrimoniais para assentar seu poder contra o direito carismático deseus opositores.

\section{Normas de direito e dinâmicas econômicas}

Ainda que não se possa subestimar sobretudo o al cance da racionalização interna (ou formal), a dimensão externa tem implicações muito mais imediatas para a sociologia econômica. Lembremo-nos a esse propósito que, ao abordar a história econômica, Weber (1991) inscreve-se explicitamente na esteira dos questionamentos de K arl M arx, já que seu projeto visa também a interrogar as relações entre as diferentes esferas da atividade social. Weber põe em evidência a congruência entre certos fenômenos que participam diretamente do movimento de racionalização do mundo moderno: 0 capitalismo, por exemplo, só pôde desenvolver-se constituindo a empresa em um quadro jurídico apropriado, isto é, sobrea base de um direito positivamente avaliável. 0 capitalismo não é, pois, simplesmente um fenômeno econômico: para funcionar, nota Weber, ele tinha necessidade de um direito com o qual se pudesse contar, tal como uma máquina. Por isso, W eber não acreditava na lógica marxista das instâncias. Ele se desfaz explicitamente de tal crença afirmando que não existe no capitalismo nenhum fator decisivo que favoreça a racionalização do direito ${ }^{4}$. A uma explicação determinista e monocausal, ele contrapõe uma abordagem dialética e pluridimensional. Trata-se, falando de outra maneira, de um complexo de variáveis quefavoreceu o desenvolvimento do direito à liberdade ou, se se preferir, a garantia de não ser importunado por terceiros - em particular o aparelho estatal - no domínio do juridicamente permitido. Esse tipo de relações jurídicas, conforme se verá, conduz diretamenteà configuração de relações de trabal ho no
4. Isso podeser demonstrado, segundo Weber, pelo direito inglês, que não constituiu um verdadeiro obstáculo ao capitalismo, namedidaem queaformação jurídica foi confiada a advogados (entre os quais se recrutavam os juízes), portanto a uma classe social a serviço dospossuidores. Acrescente-se, sempre nas pegadas de Weber, quea concentra ção da administração e dajustiça em Londres, além do custo elevado do procedimento judiciário, equivalia a uma ne gação da justiça para os menos afortunados. 
quadro do capitalismo moderno. A questão étanto maisatual quanto Weber se interessa pelo desenvolvimento de prescrições jurídicas que conferem poderes aos indivíduos, graças aos quais esses últimos podem regular reciprocamente, de maneira discricionária eautônoma (porém no quadro de certos limites, apesar de tudo) as relações que os envolvem.

Voltemos antes às quatro variáveis que, de uma maneira ou de outra, intervieram na racional ização externa do direito. 0 primei ro fator determinante foi 0 alargamento dos mercados. Em uma economia autárquica, 0 direito não tem ação sobre a economia; ele somente delimita, para cada indivíduo, uma esfera de liberdade determinada por fatores não econômicos. "C om o alargamento dos mercados", escreveW eber, "aqueles que estão interessados no mercado formam um grupo importante cuja influência de termina as transações jurídicas que o direito deve regular pelas prescrições que conferem poderes" (1986, p. 46). As transformações das estruturas sociais é o segundo vetor permissivo para a racionalização externa do direito. Fruto da ação de funcionários, a criação de um novo direito material responde à necessidade de um procedimento mais racional, que emana antes de tudo das classes sociais trabal hando racionalmente do ponto de vista econômico. Trata-se, em primeiro lugar, da classe burguesa, cujos interesses exigem um direito unívoco, claro, livre de todo arbitrário irracional, de toda perturbação irracional por privilégios concretos, garantindo a validez dos contratos e funcionando de maneira previsível. A aliança entre interesses burgueses e principescos é, desse ponto de vista, um fator determinante do processo de racionalização formal do direito: "A racionalização utilitarista característica de toda administração burocrática vai por seu próprio movimento ao encontro do racional ismo econômico das classes burguesas" (I dem, p. 194). O utras classes sociais (o campesinato, a burguesia na Antigüidade) puderam, entretanto, interessar-se por essa formalização: assim, as XII tábuas, sob as quais estava transcrito o direito da cidade romana, definiam elas mesmas normas gerais e abstratas que consagram um verdadeiro compromisso entre classes sociais. A burocratização da atividade orgânica das comunidades fornece o terceiro ingrediente ao coquetel da racionalização externa. Tal movimento está ligado à necessidade de poder dos soberanose dosfuncionários. A burocratização do Estado moderno incita à racionalização da jurisdição. Torna-se assim mais fácil encarar as reivindicações dos grupos de interesses, e opor sua própria ética racional à irracionalidade das camadas e classes contestadoras. Enfim, como os comerciantes das cidades estavam preocupados com os contratos redigidos em boa e devida forma, a 
urbanização constitui o quarto e último parâmetro que pôde ser mobilizado em favor da racionalização externa do direito.

Sob a ação desses diferentes fatores, o direito privado e o direito público viram-se consideravelmente modificados. Suas transformações tiveram impactos diretos na noção de contrato (enotadamentenaquela de contrato de trabalho), cuja questão, defato, écentral na sociologia weberiana do direito eé, por vezes, a essa única dimensão - de maneira equivocada, a meu ver que é reduzida a contribuição de W eber nesse campo de análise 5 . Para ser mais exato, as observações consagradas à racional ização das práticas contratuais ocupam uma parte importante do capítulo II da Rechtssoziologie. N essa parte, dedicada à criação dos direitos subjetivos, Weber sustenta que a racionalização jurídica se desdobra por ocasião da passagem do "contratoestatuto" em direção ao "contrato-função". O s contratos-estatuto estão na origem dos atos mágicos e simbólicos que, na maior partedas vezes, dependem da fraternalização: um indivíduo torna-se o pai, o escravo etc. de outro. Para retomar os termos de Weber, eles implicam uma mudança na situação jurídica e no habitus social dos contratantes. U ma das conseqüências dessa personalização do contrato é que a responsabilidade contratual não engaja a fortuna do devedor, mas o corpo desteúltimo. Assim, em caso denão-pagamento,

[... o queo credor podetomar éa pessoa do devedor, a qual ele podematar, prender como refém, manter como empregado doméstico, vender como escravo; ali ondevários credores estão presentes, o devedor é cortado em pedaços, como se supõe por uma passagem das XII tábuas; o credor pode igualmente se instalar na casa do devedor (Idem, p. 59).

Q uanto ao contrato-função, ele éo quadro no qual são fornecidas prestações concretas que não engajam o estatuto das pessoas. Se ele serve ao desenvolvimento econômico, sua origem é um "fenômeno geral e regulamentado entreassociados de uma comunidade política ou econômica, mas somente no domínio não econômico, ou seja, como troca de mulheres entreclãs exógamos" (Idem, p. 51). Com o uso da função monetária na manipulação dos metais, o desenvolvimento do empréstimo, o reconhecimento do direito à liberdade etc., os contratos-função se desenvolvem. C ertamente as resistências são múltiplas, e Weber dá conta delas abundantemente. $M$ as historicamentehá de fato congruência entre racionalização dos procedimentos contratuais e desenvolvimento das trocas econômicas; trocas
5.A tese de Coutu (1995) permite fazer justiça aessasimplificação abusiva. 
mudas - para retomar a expressão de W eber - pois desprovidas de todo formalismo mágico.

A exportação do esquema institucionalista: Richard Ely e a democracia econômica

D ado queo mercado detrabalho não écertamenteum mercado no sentido walrasiano do termo, as relações de trabalho constituem, desde muito tempo, um eixo de reflexão considerável para os sociólogos da economia. $0 \mathrm{~s}$ estudos deW eber, dequem al guns lineamentosforam anteriormenteesboçados, convidam assim a entender o direito como uma das peçasimportantesa concorrer diretamentepara as regulações econômicas. Esse postulado faz parte de um conjunto de hipóteses que está na origem de um ponto de vista institucionalista, cuja fama, conforme veremos a partir de agora, ultrapassa rapidamente as fronteiras alemães. $0 \mathrm{~s}$ Estados U nidos constituem, desse ponto devista, um lugar deacol hida particularmentefecundo.

\section{Da escola histórica alemã à economia institucionalista norte-americana}

O laço entre a escola histórica alemã e a tradição institucionalista americana está hoje claramente estabelecido. Em uma palavra, recorde-se simplesmenteque os anos de 1870 e 1880 constituem, para os Estados U nidos, uma virada importante: sob o pano de fundo da depressão econômica e de movimentos sociais (greves, manifestações, sucessos do proselitismo dos " $\mathrm{C}$ a valeiros do trabal ho"), eles registram a insatisfação crescente de jovens estudantes - John Bates Clark, H enry Carter Adams, Richard T. Ely, Edmund J. James, Simon Patten, Edwin R. A. Seligman e outros - com as teorias econômicas dominantes. As alternativas intelectuais que esses filhos de boa família, formados na cultura protestante (à exceção de E. Seligman), desejam promover beneficiam-se diretamente dos ensinamentos colhidos quando de seus estágios na Alemanha, momentos privilegiados por ocasião dos quais eles se impregnam das teses da escola histórica. D e volta a seu país de origem, esses jovens pesquisadores americanos estão decididos então a de senvolver um ponto de vista que se socorre, em ampla medida, da abordagem germânica. A declinação organizacional do projeto toma forma com a American Economic Association, batizada em 1885. Fundada graças ao élan decisivo de Richard Ely (1886a), essa associação quer ser um lugar aberto ao vento da revolta e, por oposição às abordagens do tipo lai ssez-faire, promove métodos de investigação indutivos, históricos e estatísticos (cf. H amilton, 
1919). Em 1918, os estatutos da associação precisam explicitamente o projeto: "as instituições- enão maiso valor - serão daqui em dianteo objeto da ciência econômica. 0 termo 'institucionalismo' é então proposto pela primeira vez para designar a escola de pensamento econômico na qual se formarão todos aqueles que aderirem a esta carta" (Guéry, 2001, p. 19).

Richard T. Ely (1854-1943) éum dos pais dessa economia institucionalista. D epois dos estudos em Columbia, Ely estagia trêsanosem H eidel berg, onde obtém um doutorado em filosofia $(1879)^{6}$. D e volta aosEstados U nidos, contribui para adifusão dasteses da escola histórica alemã, o queo leva, aliás, a seenvolver em uma M ethodenstreit americana com seu colega Simon $\mathrm{N}$ ewcomb, matemático, físico eastrônomo cedo convertido ao ponto devista marginalista. Professor no D epartamento de H istóriae Política daU niversidade J ohn H opkins (a partir de 1881), depoisna U niversidadedeW isconsin (a partir de 1892), Ely distingue, sem grande originalidade, dois tempos da economia política: 0 da escola inglesa ( $M$ althus, Ricardo, M ill) daquele da escolaal emã. A primeira, ortodoxa, caracteriza-se, segundo ele, por um andamento dedutivista, uma propen são a raciocinar sob a base do simples princípio do Selfishness, por uma ausência de referênciasestatísticas ehistóricas, por uma valorização do lai ssez-faire, por uma tendência a cindir os fenômenos econômicos dos outros fatos sociais, pela fraqueza dos serviços que ela pode prestar para aação prática, pelo irreal ismo desuas teses (como, por exemplo, a da igualização das taxas de lucro). Ely posiciona-se, assim como Weber, à sombra dos trabal hos da segunda escola - aquela que encarna os nomes de $\mathrm{H}$ ildebrand, Knies, Roscher eoutros:

Eles tomaram o nome deescola histórica a fim desealiar àsgrandes transformações no domínio da política, do direito e da teologia. Eles estudaram o presente à luz do passado. Adotaram a experiência como um guia eavaliaram o queiria advir por referência àquilo que foi. Esse método pode também ser chamado de experimental. É o mesmo método que deu excel entesfrutosna ciênciafísica (Ely, 1883, p. 233).

A experiência ea experimentação em questão tomam forma aqui graçasà história, ao tratamento estatístico ou, ainda, ao método comparativo. U ma dupla exigência é assim afirmada: aquela da empiria, por um lado - "a primeira coisa é reunir os fatos" (I dem, p. 234) -, e aquela da ruptura com uma concepção muito estreitamente individualista dos homens, por outro lado - "como Blackstone sublinhou, o homem éfeito para viver em sociedade" (Idem, p. 234).
6. Para mais detalhes da trajetória de Ely, bem como as de outros economistas, levados no início decarreira pela esperança socialista (J . B. Clark, por exemplo, que terminará por adotar um ponto de vista marginalista), ver Ross (1991, pp. 106 ss.). 
0 quedizer, mais precisamente, dasquestões sobreas relações detrabalho? Para Ely (1886b), três fatores explicam queos assalariados estejam em situação de inferioridadeno mercado de trabalho. 0 primeiro está relacionado à imperfeição desse mercado particular eàs desigual dades que resultam daí. 0 economista constata empiricamenteo quanto a existência decoal izões deempregadores pode prejudicar os assal ariados. M onopsônios e oligopsônios de empregadores, ou, dito de forma direta, o conluio desses últimos (por meio principal mente das associações profissionais), tornam-se fonte de iniqüidades, o quesetraduz concretamenteem práticas discriminatórias em relação a minorias, imigrantesemulheres. Esses modos degestão são tanto maiscarregados deinjustiça quanto a mobilidade dosassal ariadosélimitada pela perda de direitos detempo de serviço (eoutros direitos associados) quea mudança de uma empresa a outra acaba acarretando. 0 segundo fator relaciona-se ao fato de que, a despeito dos direitos políticos adquiridos no século XIX pelos trabalhadores, as relações empregadores-empregados permanecem amplamentemarcadas pela cunha do autoritarismo. A ausência de democracia industrial está na origem de múltiplos problemas: fraca implicação dos assalariados em seu trabalho, propensão a abandonar as empresas nas quais as relações de trabalho tenham se tornado insuportáveis, conflitos de trabal ho etc. Ely relaciona a insegurança econômica como o terceiro fator determinante das desigualdades que estruturam as relações entre empregadores eassalariados. Ele denuncia sobretudo os danos causados pela mercadorização do trabalho, o quetorna osassal ariados vul neráveisaosmais diversosacasos (a boa vontade do empregador, acidentes detrabal ho, doenças etc.).

\section{Democracia e economia}

D iante da incapacidade flagrante do mercado de trabalho de reabsorver demaneira autônoma as dificuldades eas iniqüidades que Ely e, mais geralmente, os economistas institucional istas untados de ciência histórica à moda alemã põem em evidência, o que se deve fazer? Para Ely, como para J. B. Clark ou H. C. Adams, a esperança socialista está associada ao advento de uma democracia industrial, tendo a grande empresa cooperativa como seu local privilegiado de desenvolvimento. "N ossa época émais democrática do que as outras, pois elaé mais cristã", escreve Ely na introdução de uma série de três artigos que aparecem em 1887 no H arper's N ew M onthly M agazine. Confiante na fraternidade dos homens, Ely estima que o desenvolvimento das grandes empresas por ações traz uma solução ao autoritarismo tradicio- 
nal dos donos de empresa, pois elas carregam consigo um princípio de democracia industrial (cf. Ely, 1887a). M ais do que as outras, as empresas financiadas por capitais negociados em bolsas, com efeito, podem desenvolver suas capacidades produtivas e encorajar a poupança. Sua estrutura as incita sobretudo a delegar as diferentes tarefas de produção e de gestão, por exemplo, àqueles que possuem as competências para isso. D essa forma, porse-ia um ponto final no autoritarismo patronal e, sob o modelo da cooperativa, vislumbrar-se-ia a tomada da gestão das empresas pelos seus próprios empregados (cf. I dem) ${ }^{7}$. Ely não é, no entanto, completamente ingênuo. Ele sabe dos perigos e dos limites da grande firma industrial. Confiar as funções de organização e de direção à gerência, por si só, não é suficiente. Ela pode desperdiçar os recursos que estão sob sua alçada e dar provas de ineficiência na realização de suas tarefas. $N$ ão écerto, além do mais, que os assal ariados teriam asseguradas condições de trabal ho decentes. A propensão ao açambarcamento monopolístico é, por fim, um perigo que ronda sempre, com sua coorte de métodos duvidosos (produzir a baixo custo para provocar a falência do concorrentee em seguida adquiri-lo) ede danos para os assalariados implicados nesse processo. D aí por que a regulação econômica e social das empresas deve ser objeto de uma responsabilidade diferenciada, segundo pertençam elas a setores de indústrias com rendimentos constantes, decrescentes ou crescentes. N os dois primeiros casos, é possível satisfazer-se com o princípio competitivo, na medida em que a tentação monopolística é diminuta. No último caso, ao contrário - como por exemplo no setor do gás - , a interven ção se impõe. "O espaço econômico coberto pelos rendimentos crescentes deve ser abandonado pelas empresas em prol do governo federal, quer seja do Estado apenas, quer seja de combinações associando o Estado com suas diferentes subdivisões, com as municipalidades devendo vir em primeiro lugar" (Ely, 1887b, p. 262).

0 raciocínio de Ely mistura múltiplos ingredientes tipicamente alemães: pano de fundo deísta, cuidado com a acumulação de dados empíricos, denúncia das desigualdades sofridas pelos assalariados, engajamento em favor de certa intervenção estatal no curso dos negócios econômicos e, por fim, esquema de análise tipicamente historicista. G raças à aliança entre cristianismo e teoria econômica, o conjunto fica a serviço de um projeto ético que tem no combate às desigualdades naturais e sociais uma de suas manifestações mais tangíveis. A ligação com a escola histórica se esclarece ainda mais se se recorda que a economia social (die Volkswirsschaft), tal como a concebem os socialistas de cátedra,
7. No espírito deEly, de mocraciaindustrial não significa o apagamento das diferenciações estatutárias esociais. "Q uando as empresassetornarem verdadeiras cooperativas respeitadoras do fator trabalho, os capitãesdeindústrianão desaparecerão. A hierarquia écompatível com a mais perfeita das democracias" (Ely, 1887b, p. 260) 
8. $N$ au eSteiner (2002) mostraram que a preocupação moral éum traço comum à sociologia durkheimiana eà escolahistóricaalemã. A des peito de diferenças não negligenciáveis, Durkheim eSchmoller de dicam, com efeito, um interesse comum pela questão das reformas e dajustiça social. 0 institucionalismo americano, Ely em primeiro lugar, inscreveseus trabaIhos plenamentenesse mesmo conjunto de preocupações.

*A data entrecolchetes refereseàedição original daobra, indicadanaprimeiravezem queaobraé citada. $N$ asdemaisocorrênciasindica-seapenas adatadaedição utilizada peloautor (N.E.).

9. Se, por um lado, não sucumbeà tentação de empirismo radical, esse aluno de Ely não renuncia contudo a unir teoriae prática. Participa, assim, de grandes questionários sobre 0 movimento operário, sobre a imigração, e, a título dessaparticipação, acabará tendo uma influência na legislação operáriaamericana. Tornasemembro, ademais, decomissõesindustriais encarregadas de fixar 0
[...] não consistesimplesmente em uma sociedade de produção. 0 queimporta antes detudo não ésaber como sepode produzir o mais possivel, mas, antes, como os homens vivem, atéque ponto a atividade econômica realiza as finalidades morais da vida, os postulados dejustiça dehumanidadee demoralidadequeseimpõem atoda sociedade humana (Schoenberg, apud D urkheim, 1975, p. 270).

Ely argumenta paralelamente em favor de uma abordagem econômica na qual a justiça social constitua o horizonte privilegiado ${ }^{8}$. $M$ as, como se pode facilmente admitir, as análises desse autor permanecem insatisfatórias para opor-se à escola inglesa, dotada, independentemente do que se pense, de um fôlego teórico muito mais potente do que aquele dos heterodoxos americanos. A indignação e o investimento empírico não são suficientes para fundar uma teoria das relações de trabalho. É justamentetal fragilidade que as industrial relations irão deplorar, e continuarão depois sempre a fazêlo. Em 1958, John T. Dunlop o reconhece na primeira hora:

[...] o campo das relações industriais de hoje pode ser descrito nos termos de ulian H uxley: montanhasdefatosforam empilhadosnas planícies daignorânciahumana... 0 resultado éuma superabundância de materiais brutos. M assas inteiras dedadosjazem ali, inutilizados ou mobilizados, quando éo caso, ou então demaneira parcial. A empiria tomou o lugar dasidéas. A teoriaficou paratrás em favor deum empirismo expansivo ([1958]* 1970, p. vi).

Se essa constatação permanece ainda parcialmente válida hoje em dia, ela merece contudo ser nuançada. N o corpus dos trabal hos institucionalistas encontram-se traços detentativas originais de formalização teórica quetanta falta fazem a inúmeras investigações empíricas.

\section{J. R. Commons, herdeiro de Richard Ely}

É o queacontece, antes detudo, com as pesquisas deJ. R. Commons9. Ele manifesta primeiramentea vontade de sistematizar, depois dos economistas alemãese deR ichard Ely, as etapas históricas quemarcaram atransformação progressiva das articulações entre mercado erelações detrabal ho. Asanálises a que se dedica $C$ ommons sobre o movimento operário têm, assim, raiz em um conjunto de reflexões consagradas à lógica de desenvolvimento do sistema econômico. 0 capitalismo percorre as etapas sucessivas do capitalismo comercial, capitalismo do empregador e depois capitalismo bancário (cf. 
Commons et al., 1918). Em segundo lugar, ele traz as regras e suas negociações para o coração das relações econômicas eesboça, nesse passo, uma verdadeira teoria das transações (cf. Bazzoli, 1999). A influência de Sidney e BeatriceW ebb éaqui explícita. No início dosanosde1900, CommonslêOn industrial democracy. À maneira do casal inglês, ele posiciona as regras no centro de sua análise, a fim de mostrar quea prática operária ea ação coletiva podem desembocar na produção denormas, da mesmaforma queinfluenciar as atividades de trabalho e estabilizar os conflitos de interesse. M ais ainda: insatisfeito com a lógica individualista que funda as análises da relação de trabal ho sobre o contrato, C ommons desenvolve uma reflexão institucionalista que assegura todo lugar ao col etivo eà organização hierárquica.

0 artigo seminal que Commons consagra aos Shoemakers, em 1909, fornece uma bela ilustração empírica do que se acabou de mencionar. 0 artigo inscreve-se explicitamente na tradição alemã. 0 autor o reconhece, aliás, de bom grado, uma vez que compara seu trabal ho ao deK arl M arx, de Gustav Schmoller edeK arl Bücher. Ao primeiro Commons concedeo interesse por uma apreensão do mundo em termos de etapas econômicas. M as, em vez de raciocinar a partir do modo de produção e de uma teoria da maisvalia, ele propõe priorizar uma explicação pelos mercados. A evolução industrial pode ser lida, com efeito, pelo prisma do alargamento incessante do espaço de difusão de bens produzidos. Convém estar atento, a esse propósito, às múltiplas perturbações que vêm falsificar a eficácia e a boa harmonia no seio da comunidade de produtores (fabricação de produtos demá qualidade, utilização de trabalho de prisioneiros ou do trabalho de crianças, recurso a assalariados não grevistas...), uma série de problemas que suscitam o emprego de medidas protecionistas. Q uanto a Schmoller eBücher, Commons Ihes felicita por terem evitado os caprichos da abstração, o que nem por isso os escusa, acrescenta ele, da fragilidade de suas tipologias.

A fim de apoiar empiricamente seu próprio quadro de análise, Commons se detém no caso dos Shoemakers. Ponta-de-lança dos combates e dos conflitos quemarcam a industrialização dos Estados U nidos, esses fabricantes de calçados compõem uma classe de homens qualificados, pulverizada no conjunto do território, perpetuamente ameaçada pelas mudanças industriais e comerciais, mas que, graças à sua capacidade de organização, soube sempre remediar os riscos relacionados à extensão crescente das fronteiras do mercado. Como indica explicitamente o subtítulo do artigo ("A sketch of industrial evolution"), trata-se de tomar como pretexto o estudo de um grupo profissional particular para, à maneira dos pesquisadores da escola valor dos salários em caso delitígio em uma profissão. Em suma, Commons confessa-se partidário de um capitalismo razoável epopular, quesaiba conferir ao sindicalismo o lugar que elemerece. 
histórica alemã, determinar os estágios da evolução industrial. A aproximação não éforçada. M esmo por tradução interposta, o livro deBücher (1893), consagrado à evolução das sociedades industriais, serve explicitamente de referência a Commons. 0 método utilizado é simples: consiste em supor que, para diferentes tipos de organização dos Shoemakers - Commons distingue seis tipos, que vão de The company of Shoemakers (Boston, 1648) ao Theboot and shoeworker'sunion (1895) -, correspondem estágios definidos de evolução industrial. Reconhece-se aqui, aliás, outra hipótese tipicamente alemã: aquela em virtude da qual a extensão do espaço mercantil é o verdadeiro motor da evolução das formas industriaise, em conseqüência, detipos de regulação das relações de trabalho. 0 método consiste, pois, em dar prioridade a uma variável explicativa para tornar inteligível a razão daquela que se deseja explicar (abordagem por "hierarquia dos fatores").

N ão detalharei os múltiplos estágios que J. R. Commons comenta longamente nesse artigo. Em vez disso, limito-me à primeira etapa, a qual, em meados do século XVII, conduz os Shoemakersa regulamentar sua profissão (instauração de uma comissão, de um código da profissão, de uma tabela de penalidades etc.), em conseqüência da produção de mercadorias demá qualidade por alguns deles. D efato, a regulamentação proíbea fabricação de calçados no domićlio dos clientes, a fim de melhor favorecer o controle dos sapateiros menos competentes pel os artesãos qual ificadose, in fine, para repelir esses últimos do mercado de trabal ho do calçado. Reconfigurar dessa maneira os espaços dos mercados de bens e de trabal ho é algo pleno de conseqüências sociais: com o risco de serem expulsos da profissão, caso infrinjam as normas de qualidade, os Shoemakers pouco qualificados deverão daí em diante trabal har em oficinas e não mais de acordo com a encomenda do cliente (que fornecia o local, o material e a alimentação), fazendo com quefunções anteriormente separadas (as de comerciante, mestre e operário) sejam doravante unidas em um único estatuto. Commons igualmente mostra como a passagem de um custom-order market de vizinhança a um mercado mais amplo participa diretamente dessa evolução. A instauração de novas normas profissionais vai de par com as transformações técnicas (estoque de mercadorias, venda em lojas, desenvolvimento do shop

10. Trata-se de um trabalho em que o executantenão forneceama téria-prima para aconfecção do produto (N.T.). work, além do trabalho por encomenda ${ }^{10}$ etc.). Por fim, o desenvolvimento econômico tem um impacto forte sobre as classes sociais. Por meio das mutações mercantis, regulamentares e técnicas, o mestre artesão muda de estatuto para adquirir o de comerciante e de empregador. Ao longo de toda a exposição dos diferentes estágios que se seguem, Commons dá conta, de 
uma maneira similar, das articulações evolutivas entre configurações mercantis, relações de trabalho e laços entre produtores e consumidores. $\mathrm{Na}$ linha direta da escola histórica alemã, ele oferece assim um esquema de análise original das condições de emergência das relações econômicas nos EstadosU nidos.

\section{Conclusão}

C ada um a sua maneira, $M$ ax Weber e Richard Ely fizeram frutificar as hipóteses e os pressupostos metodológicos da escola histórica alemã, a fim de alimentar aquilo que podemos considerar hoje o corpusfundador da sociologia econômica. Weber convida-nosa levar a sério as regras do direito e, em conseqüência, a não tomar o capitalismo, as relações de trabalho e a organização das empresas como fenômenos econômicos encerrados em si mesmos. Tal posição é fortalecida por múltiplas outras obras que Weber consagra ao trabalho industrial, à história econômica, à religião, à arte e à ciência (cf. Weber, 1964; 1969; 1991; 1992; 1998; 1999; 2000). Em todas essas representações, o sociólogo alemão põe em evidência um duplo resultado. Em primeiro lugar, aponta para a existência de afinidades mais ou menos eletivas entre a economia e os outros mundos sociais, de onde a impossibilidade de pensar o econômico de maneira pura e autônoma. E não cessa, em seguida, de ir ao encalço das múltiplas tensões que opõem, tanto no sistemajurídico como al hures, racionalização formal eracionalização material. D esses postulados e intuições, somos ainda hoje devedores (cf. Supiot, 1984; Weis, 1989). Ely trilhou, por seu turno, a via de uma ciência das instituições econômicas em que um dos méritos é fazer voar em pedaços a oposição entre economia e política, e, de certa maneira, a célebre partição entre julgamentos de fato e julgamentos de valor. Instaurando assim a exigência democrática no coração da reflexão sobre as relações econômicas, Ely não apenas vivificou um veio intelectual - do qual Commons, mas também Selig Perlman (1928), ou ainda John T. Dunlop (1958) são os mais célebres representantes - mas, de manei ra diferente de Weber, precocemente também ele apresentou as balizas de uma reflexão sobre o lugar da ética na ação econômica. Eis por que o cuidado em não separar moral e economia seja tal vez, finalmente, a herança maior da escola histórica alemã à sociologia econômica contemporânea. 


\section{Referências Bibliográficas}

BAzzoLI, L. (1999), E conomie politiquedeJ ohn R. Commons essai sur l'institutionnalisme en sciencessociales Paris, L'H armattan, Études d'économiepolitique.

Bücher, K. (1893), D ieEntstehung der Volkswirtschaft. T übingen (edição em língua inglesa, Industrial Evolution. N ova York, Augustus M. Kelley, 1901).

Comm ons, J. R. et al. (1918), H istory of labor in theU nited States. N ova York, M acmillan Company, v. I.

Coutu, M . (1995), “M axWeber et les rationalitésdu droit”. D roit Société, 15, Paris/Q uébec, LGDJ/Presses del'U niversité de Laval.

D un LoP, J. T. (1958), Industrial relati onssystems. N ova York, H olt (reedição C ardonbale and Edwardsville, Southern Illinois U niversity Press, 1970).

D urkheim , E. (1975), "Lascience positive dela moraleen Allemagne”. In: Textes

1. Elémentsd'unethéorie sociale. Paris, M inuit, pp. 267-354 (originalmente publicado em Revuephilosophique, n. 24, 1887).

ELY, Richard. (1883), "T he past and the present of political economy". The 0 verland M onthly, 9 (II): 225-235, set.

. (1886a), "Report of the organization of the American Economic Association". American Economic Review, 1: 5-46, mar.

. (1886b), Thelabor movement in America. N ova York, T homas Y. C rowell. . (1887a), "The nature and significance of corporations". Harper N ew M onthly

M agazine, pp. 970-977.

. (1887b), "T hefutureof corporations". H arper N ew M onthlyM agazine, pp. 259-266.

GuÉRY, A. (2001), "Propriété, droit et institution dansl'institutionnalismeaméricain". Cahiersd'économie politique, 40-41: 9-38.

H Am ILton, Walton H . (1919), "T he institutionnalist approach to economic theory". American Economic Review, 9: 309-318 (Suplemento).

H odgson, G. (1994), "T he return of institutional economics". In: Sm elser, N . J. \& Swed berg, R. (eds.). Thehandbook of economic sociology. N ova York/Princeton, Princeton U niversity Press/Russel Sage Foundation.

Lallem ent, M . (2004a), "Penser lesinstitutions: paradigmes d'hier, débats d'aujourd'hui”. Sociologia del Lavoro, 93: 62-75.

. (2004b), “M ax Weber, la théorie économique et les apories de la rationalisation économique". Cahiersdu centrederecherchehistorique, 34: 93-115, out.

N au, H . H . \& Steiner P. (2002), "Schmoller, D urkheim and old european institutionalist economics". Journal of Economicl ssues, 4 (XXXVI): 1005-1024, dez.

PerLm an, S. (1928), Thetheory of the labor movement. N ovaYork, TheM ac M illan Company (reedição N ova York, Senty Press/Augustus M . K elley Publishes, 1970). 
Ross, D . (1991), T he origins of American social science Cambridge, C ambridge University Press.

SCH U M PETER, J. (1983), H istoi re del'analyse économique. 1a edição britânica 1954. Paris, Gallimard, 3 v.

SupIot, A. (1984), "D élégalisation, normalisation et droit du travail”. D roit social, 5: 296307, maio.

Swed berg, R. (1998), M axWeber and theidea of economic sociology. Princeton, Princeton U niversity Press.

W eber, M ax. (1964), L'éthique protestantee l'esprit du capitali sme. 1ª edição 1904-1905. Paris, Plon.

. (1969), Economieet soci été. 1a edição 1922. Paris, Plon. . (1986), Sociologi edu droit. 1a edição 1960. Paris, PU F, Recherchespolitiques. . (1991), H istoireéconomique esquissed'unehistoire universelledel'écon omieet dela sociééé. 1a edição 1923. Paris, Gallimard, Bibliothèque des sciences humaines. . (1992), Essai sur la théoriedela science. Paris, Plon, Presses pocket (tradução parcial da versão alemã disponível em: G esammel teA Aufätzezur W issenschaftlehre, T übingen, J.C.B. M ohr [Paul Siebeck], UTB, 1967). . (1998), Sociologie dela musique. 1ạ edição inglesa 1958. Paris, M étailié. . (1999), Essays in economic sociology. Princeton, Princeton U niversity Press (editado por R. Swedberg). . (2000), Confucianismeet taoïsme. 1a edição 1915. Paris, Gallimard.

W EISs, J. (org.). (1989), M axWeber H eute. Frankfurt am M ain, Suhrkamp, Taschenbuch W issenschaft 711.

\section{Resumo}

Raízes alemães da sociologia econômica

O texto recupera afonteclássica weberiana edaEscolaH istóricaAlemã paraaformação da economia institucional ista no contexto acadêmico norteamericano dasúltimas décadas do século XIX. Para isso, retoma as reflexões deW eber em torno da sociologia do direito e a conexão entrenormasjurídicas eação econômica. Apresenta em seguida a sua recepção do outro lado do Atlântico como grandementedevedora dasfiguras respectivas deRichard T. Ely, destacado representante de uma geração de estudantes formados pelo ambiente cultural alemão, eem seguida de J. R. Commons, leitor do primeiro. 0 artigo também mostra as relações entre os temas da democracia industrial eda grande empresa cooperativa, nosEstadosU nidos, com a aquela tradição intelectual, estabelecendo assim as condiçõeshistóricas para o surgimento posterior da sociologia econômica. Sugere, dessa forma, que as afinidades eletivas entrea economia eas outras esferas do social, uma abordagem de 
raiz weberiana, têm explicitada a sua linha de continuidade encontrada nas classificações disciplinaresmais recentes.

Palavras-chave: Rechtssoziologie; I nstitucionalismo; Sociologia econômica.

\begin{abstract}
The German roots of economic sociology

Thetext reassesses the use of W eber and the G erman $\mathrm{H}$ istorical School as classical sources in theformation of institutionalist economics in theU S academic context during thefinal decades of the $19^{\text {th }}$ century. Thisaim in mind, it turnsto Weber's writings on the sociology of law, and theconnection between juridical norms and economic action. Subsequently, thetext presentsthereception of hiswork on theother side of theAtlantic, in particular via the figures of R ichard T. Ely, the leading figure of a generation of students influenced by the German cultural environment, followed later by J. R. C ommons, a close reader of the former's work. Thearticleal so focuses on the relations between thisintellectual tradition and the themes of industrial democracy and large cooperative companies in the U nited States, a process that established the historical conditions for the later emergence of economic sociol ogy. In conclusion, it suggests that the 'elective affinities' between economics and other social spheres, an approach rooted in Weber, help explain lines of continuity found in morerecent disciplinary classifications. Keywords: Rechtssozi ologie; Institutionalism; Economic sociology.
\end{abstract}

Recebido em 5/3/2005 e aprovado em $1 / 9$ / 2005.

Michel Lallementéprofessor de sociologia do Laboratoirel nterdisciplinairepour laSociologieÉconomique(LISE) - CNRS CN AM. Email: lallemen@cnam.fr. 